\title{
Comprehensive Textbook of Echocardiography
}

\section{Editor Navin C Nanda}

Published by Jaypee Brothers Medical Publishers (P) Ltd.

Encyclopaedia on Echocardiography

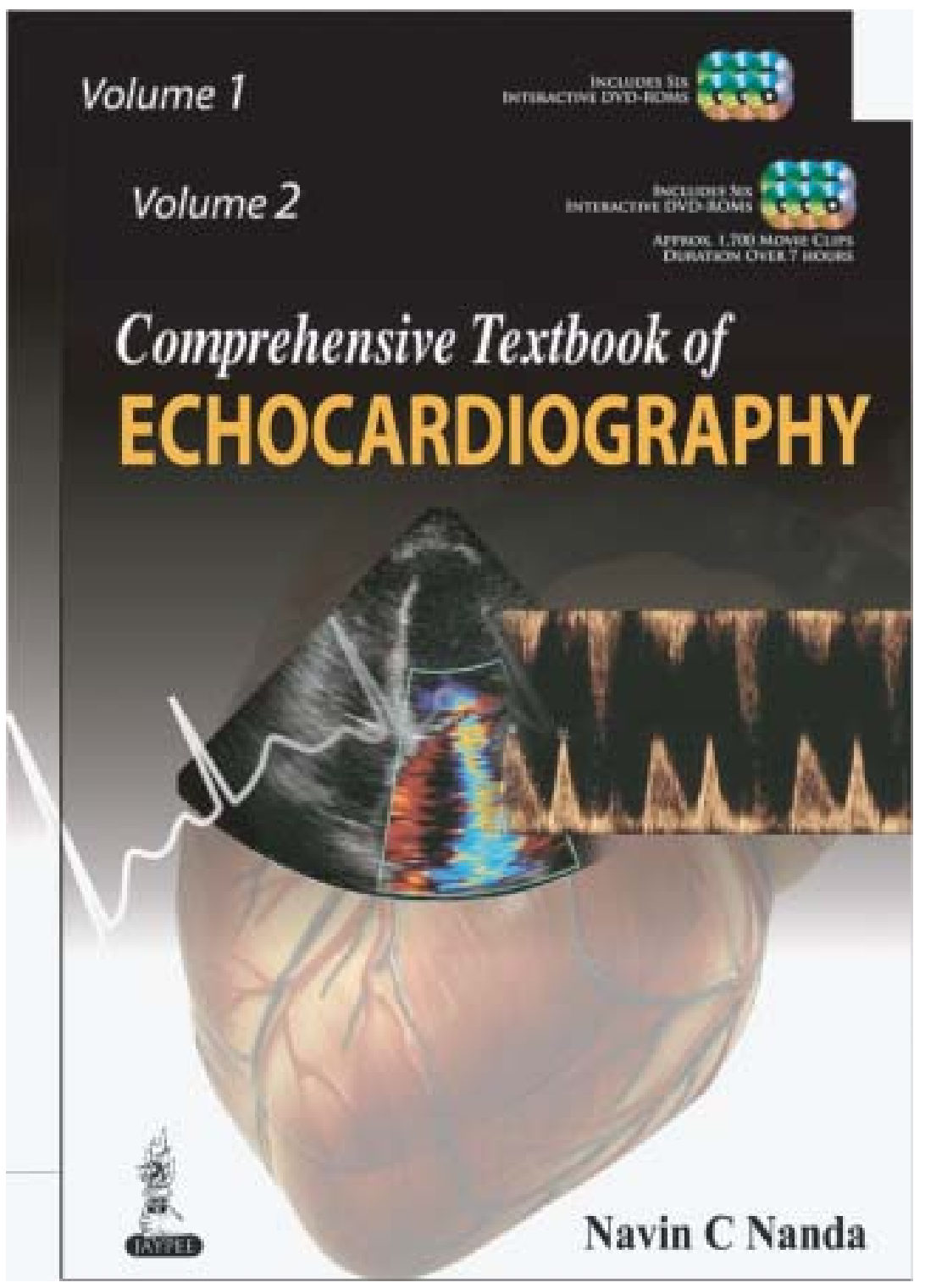

The year 2014 brings a good news for us : at last we have a complete book on Echocardiography "Comprehensive Textbook on Echocardiography". The book is edited by Prof. NC Nanda, today there is hardly anyone whose name might be more appropriate than Prof. Nanda to carry out such monumental work. We have got a good number of internationally reputed authors whose books are useful and informative both for the learners as well as practicing cardiologists. But a complete compilation of the current knowledge on echocardiography under a single 
title was always felt to be needed. Prof. Nanda, "Father of Echocardiography" takes the parental duty to fulfill our needs.

The book comes in 2 volumes. First volume contains 1114 pages and 50 chapters. Second volume contains 955 pages and 35 chapters. Numerous illustrations are included that make the use of the book practicable. Additionally 6 interactive DVD-ROMs with 1,700 movie clips with duration 7 hours are provided with the book. What a wonder!

The beauty of the book is that each chapter is written by the person(s) most competent for the topic. Thus it is not only a product of multiauthors but also multi-national. Authors belong to different centres of different countries ranging from Saudi Arabia to India to USA to Brazil. There is a point to note that the book is produced under the aegis of International Society of Cardiovascular Ultrasound and Indian Academy of Echocardiography. (I wish author(s) from
Bangladesh might have contributed if invited as Bangladesh Chapter, ISCU is an active one.)

The book starts with " History of Echocardiography" and towards end there is a chapter on "The future of Echocardiography and ultrasound". In between these two chapters the book deals from basics to advanced modality of the echocardiography. There are two chapters on cardiac MRI and cardiac CT imaging. Thus we travel from the past to look into the future aspects of Echocardiography. Indeed it will be useful for the juniors and seniors alike.

For every library of medical profession, personal and institutional, this book deserves its place as a treasure.

Prof. Nanda will be remembered for the services he has been rendering for the propagation of echocardiography over the decades with special care and sympathy to the developing countries like Bangladesh. As the editor of this book, his name will be permanently recorded in the history of medical profession. We salute him! 